\title{
Linx
}

Revue des linguistes de l'université Paris X Nanterre

$80 \mid 2020$

L'héritage de Jean Dubois et Françoise Dubois-Charlier

\section{Subordinate Interrogatives and Subordination in Oral Speech: Syntax and Prosody}

Subordonnées interrogatives et subordination en anglais oral : syntaxe et prosodie

\section{Laetitia Leonarduzzi and Sophie Herment}

\section{OpenEdition}

\section{Journals}

Electronic version

URL: http://journals.openedition.org/linx/6362

DOI: $10.4000 / \operatorname{linx} .6362$

ISSN: 2118-9692

Publisher

Presses universitaires de Paris Nanterre

Electronic reference

Laetitia Leonarduzzi and Sophie Herment, « Subordinate Interrogatives and Subordination in Oral Speech: Syntax and Prosody », Linx [Online], 80 | 2020, Online since 31 July 2020, connection on 05 August 2020. URL : http://journals.openedition.org/linx/6362

This text was automatically generated on 5 August 2020

Département de Sciences du langage, Université Paris Ouest 


\section{Subordinate Interrogatives and Subordination in Oral Speech: Syntax and Prosody}

Subordonnées interrogatives et subordination en anglais oral : syntaxe et prosodie

Laetitia Leonarduzzi and Sophie Herment

\section{Introduction}

\subsection{Background of the paper}

1 This paper ${ }^{1}$ takes up a part of the first author's $\mathrm{PhD}^{2} \mathrm{La}$ subordonnée interrogative en anglais contemporain (Leonarduzzi 2000, 2004), which was prepared under the supervision of Françoise Dubois-Charlier - and more particularly the chapter on subordination. The first author was one of Françoise Dubois-Charlier's last $\mathrm{PhD}$ students in Aix-en-Provence, and by the time she taught her, Françoise Dubois-Charlier had partly turned (at least as far as the study of English was concerned) to a research based on the close examination of corpora (see J. Guéron's article in this issue). The first author followed this trend. Her PhD dealt with subordinate interrogatives in modern British English and was based on a corpus of written speech (1500 examples essentially drawn from the BNC). Here, the perspective is still corpus-driven, but is turned towards oral speech. The idea is to integrate an essential aspect of the question - prosody, hence the collaboration between the two authors. The second author was also one of Françoise Dubois-Charlier's students and like the first author, later became her colleague. The present study is based on tokens drawn mainly from the ICE-GB corpus, which offers recordings of spontaneous or semi-spontaneous speech in addition to written speech. 


\subsection{Research questions and outline of the paper}

2 The addressed question is the following: how far may interrogative clauses be considered to be subordinate(d) in cases when they display subject-auxiliary (or subject-be) inversion in a sentence containing an interrogative-governing term (for instance in I said did he mind if I came in dry)? This question will lead us to first consider the internal characteristics of independent interrogatives, then the internal and external characteristics of subordinate interrogatives (from a syntactic, semantic, pragmatic and prosodic point of view), before turning to the question of subordination proper. We will end up trying to find out what contexts allow inversion.

3 We shall speak of "subordinate interrogatives" rather than "embedded questions" since our main preoccupation is the syntactic characteristics of interrogatives rather than their semantics (see $\S 2.1$.), even though the two are not completely separable. It is indeed well-known that a declarative may be used with the illocutionary force of a question, and questions are not what we are concerned with here.

4 It is to be specified from the start that we consider such sentences as I know who was here first as containing subordinate interrogatives (and not free relatives) - even though the introductory term know is not in the negation - simply by virtue of its containing an interrogative-governing verb expressing cognition (Leonarduzzi, 2004). To our mind, the contexts in which free relatives can be found in such sentences are restricted. The debate over such examples is not yet settled (see for instance Turnbull-Sailor, 2007).

\subsection{Corpus and prosodic analysis}

5 For this study, our corpus of interrogative clauses in combination with an interrogative-governing term was drawn from the ICE-GB corpus (Aarts et al., 2002), which contains one million words ( $60 \%$ are oral data). The oral part of ICE-GB includes private and public dialogues, unscripted and scripted monologues and broadcast news. The written part contains non-printed texts (correspondence and non-professional writing) as well as printed texts (academic and non-academic writing, creative, instructional, persuasive writing and reportage) We extracted 424 tokens in spoken speech and 127 in written speech (with or without an inversion).

6 Among the oral examples, 171 displayed interrogative clauses clearly containing an inversion, and 29 were ambiguous (with the wh-word as subject or with equative be see $§ 3.3 .1$. and 4.3.1.).

7 Concerning written speech, we found 20 examples of apparently subordinate clauses with inversion (setting apart 35 cases of reported speech, in which the interrogative clause is clearly independent) and 21 ambiguous examples. To which we can add 41 examples of interrogative clauses without an inversion.

8 Among the spoken examples, a selection of 167 tokens were prosodically analysed, either inverted or not.

9 The prosodic analysis was conducted following the British tradition, and in particular the system known as the three Ts (Halliday, 1967): tonality (the division into tone units), tonicity (the place of the nuclear syllable) and tone (the distinctive pitch movements). The tone unit can be separated into five components: prehead (first unaccented syllables), head (first accent), body, nucleus (syllable bearing or marking 
the beginning of the melodic movement) and tail (postnuclear syllables). Prehead and tail are supposed to contain minor information. In our examples, a tone unit boundary is indicated by a slash, the head of the tone unit is in capital letters and the nuclear syllable is underlined. Tones are not indicated in this study because they are not of interest here. Here is an example of prosodic annotation:

[1] PEOple keep saying / WHERE's Louisa

We must specify that the prosodic analysis was conducted aurally, due to the poor acoustic quality of many examples in ICE-GB (background noises most of the time, making it impossible to use a software for prosodic analysis, even though we did use PRAAT (Boersma \& Weenink, 2001) to confront our auditory analysis to the software when it was possible).

11 What we focused on for this study as far as prosody is concerned is whether there is a tone unit boundary separating the interrogative clause from the clause containing the interrogative-governing term. Another element we took into account is the presence or not of an initial accent (head) on the wh-word, or auxiliary in case of inversion, starting the interrogative clause. The last accent is very important too since it indicates the place of nucleus, which is supposed to be the most relevant word in the tone unit.

\section{Independent interrogatives}

\subsection{Interrogatives and questions}

One important distinction which must be stated from the start is the one between "interrogative" and "question". "Interrogative" is a formal category, whereas "question" is a semantic one, and is linked more specifically to illocutionary force. A type of question determines a certain set of answers (see $\$$ 2.2.2. and 3.2.1). Of course, we cannot totally separate the two, so that interrogatives have prototypical semantic features as well and are characteristically used to ask questions.

\subsection{Independent interrogatives: common characteristics}

An independent interrogative is then characterized by its syntactic, semantic, pragmatic and prosodic features.

\subsubsection{Syntax}

From a syntactic point of view, we can consider that there are two types of interrogatives: open and closed interrogatives. Huddleston \& Pullum (2002) distinguish five types of clauses, including these two types of interrogatives. Open interrogatives start with a wh- word or wh- phrase (What do you want? Who came? How did he know? Which car is best?), whereas closed interrogatives start with an auxiliary verb (do/did when no other auxiliary verb is present: Did you enjoy the play? Have you seen the secretary? Could you help me?).

Both types display subject-auxiliary inversion, except in open interrogatives when the wh- phrase is subject of the interrogative clause (Who came? What prompted you to do this? What happened?). One way of explaining the inversion in independent open interrogatives is to say that it is triggered by the fronting of the wh-word. This would 
also explain the absence of inversion when the wh- word is subject. In closed interrogatives, it is supposed to be triggered by the clause type itself (Huddleston \& Pullum, 2002). In writing, independent interrogatives are of course marked by the presence of a question mark at the end.

Open interrogatives display other characteristic features. Contrary to closed interrogatives, which are always tensed, they may contain an infinitival verb (How to convince her? see $\$$ 2.3.1.). Moreover, they may undergo sluicing (Which car? Who?).

\subsubsection{Semantics}

17 Open interrogatives prototypically correspond to open questions, that is to say that they are typically used to make an inquiry which requires no specific answer. The set of answers is open. On the contrary, closed interrogatives expect a closed set of answers (yes or no) and correspond to closed questions.

Several semantic types of questions have been distinguished (polar vs. alternative, etc.).

\subsubsection{Pragmatics}

Interrogatives are prototypically used to make inquiries, and have the illocutionary force of questions. But they may also serve various other purposes, such as making a suggestion (Why don't you stay over night?), making a request (Could you help me?), and many others.

20 Another pragmatic aspect concerns open questions. The wh- word is analysed as a variable and the wh- clause as an open proposition containing a presupposition (Huddleston \& Pullum, 2002). In Who came? who expresses a variable which is contained in the open proposition $x$ came. The question can then be paraphrased as "Who is the $x$ such that $x$ came?".

\subsubsection{Prosody}

21 From a prosodic point of view, open interrogatives are typically pronounced with a falling contour, whereas closed interrogatives are pronounced with a rising contour (Wells, 2006), although there may be some variation (Hedberg \& Sosa, 2002; Herment et al., 2014; Delais-Roussarie \& Herment, 2018). The wh- word or the auxiliary starting the question is accented in open interrogatives and negative closed interrogatives, but may be unaccented in positive closed interrogatives (Hedberg \& Sosa, 2002).

\subsection{Specific features}

Some types of interrogatives display specific syntactic and/or semantic features, and these features may become different under embedding. We shall mention hereunder only the cases of to-infinitivals and emotive modifiers, which will be useful for the rest of the demonstration.

\subsubsection{To-infinitival forms}

Independent interrogatives may contain an infinitival verb, with or without to. Huddleston \& Pullum (2002: 873) mention that the to-infinitival form is used in titles 
(What to do in the event of fire) or when the speaker is pondering over a question, especially in interior monologues (How to persuade her to forgive him? = How could he persuade her to forgive him?). They explain that in the first case, we are faced with a nonsentential construction which is equivalent to a noun phrase (How to get rich quick is compared to Five ways to get rich quick). One may wonder though whether the clause is truly independent here (Leonarduzzi, 2004). Indeed, this construction has no illocutionary force of its own, which is a characteristic of subordinate interrogatives (see $\S$ 3.2.1.). It is not used to ask a question, so that it is possible to imagine an embedding verb such as tell: I will tell you (what to do in the event of fire). On the contrary, in the case of interior monologues, the clause does have illocutionary force (the speaker truly asks himself a question), as partly mentioned by the question mark, so we may speak of an independent clause.

\subsubsection{Emotive modifiers and clefts}

Expressions such as on earth / the hell / ever are used in independent interrogatives to increase the notion of questioning:

[2] What on earth may this be?

[3] Why ever did you say that?

[4] What the hell does he want?

Another way of reinforcing the question is to highlight the wh- word through clefting:

[5] What is it that's so attractive about men's bodies?

\section{Subordinate interrogatives}

\subsection{Subordination}

We shall start this section with a general definition of clause subordination (which is a special case of what is also called hypotaxis). From a syntactic point of view, a subordinate clause is described as a clause which is dependent on another clause of which it is a constituent, directly or indirectly through a phrase. The subordinate clause has a function inside the main clause (sometimes called "superordinate" or "matrix" clause). It implies an asymmetrical relation between the two clauses (as opposed to coordination). Arrivé et al. (1986) give the following definition: "[La subordination est] une relation dissymétrique entre deux phrases dont l'une reçoit sa fonction de l'autre, sans réciprocité." ${ }^{3}$ An example with a that-clause is I know that you are right, where that you are right is the object of know, or The hypothesis that he was in the room proved wrong, where that he was in the room is complement of the noun hypothesis, the whole NP being the subject of the main verb be (wrong).

Syntactic subordination has semantic consequences on the relations between the two clauses. Let us quote Quirk et al. (1985: 919): "A major difference between coordination and subordination of clauses is that the information in a subordinate clause is often placed in the background with respect to the superordinate clause. Thus, the syntactic inequality of subordination tends to bring with it a semantic inequality which is realized by syntactic hierarchization, as well as by position." The phenomenon is clear with adverbial clauses. Quirk at al. give this example: Since he has quarreled with the chairman, he has resigned in which the since-clause is presupposed (as opposed to He 
quarreled with the chairman, and has resigned). The main clause is given more prominence than the subordinate clause.

\subsection{Internal characteristics of subordinate interrogatives}

\subsubsection{Common characteristics}

When embedded, an interrogative clause generally loses its main characteristic features (syntax, illocutionary force, prosody), while keeping its semantics.

The main syntactic feature which is lost is the subject-auxiliary or subject-be inversion. Thus, an independent interrogative such as What does Paul want will yield under embedding I wonder / I ask what Paul wants. In writing, the question mark disappears.

Dependent interrogatives also lose the illocutionary force of questions they characteristically have when independent. This is common ground for all types of subordinate clauses. In I wonder what he said? the illocutionary force of inquiry is due to the main clause rather than the subordinate clause.

31 Much has been written about the prosody of independent interrogatives, but very little to our knowledge about that of subordinate interrogatives, but it is to be expected that when subordinate, an interrogative clause loses its prosodic autonomy. We will come back to this question further down.

As mentioned above, the only feature that remains in interrogatives when embedded is their semantics. Whether subordinate or not, they define a set of answers, either open or closed. The distinction between closed and open interrogatives is kept with a difference in their syntactic features. Closed subordinate interrogatives will be introduced by the subordinators if and whether, while open interrogatives will keep the interrogative phrase they would have in the corresponding independent interrogative clause.

Another feature that is maintained in open interrogative clauses is the semantics of the wh- word or phrase as expressing a variable, and the wh-clause as expressing an open proposition.

\subsubsection{Loss or modification of specific features}

\subsubsection{TO-infinitivals}

Infinitivals may be found in subordinate interrogatives as well as in main clause interrogatives (see $\S$ 2.3.1.), but there are a few differences between them. With independent clauses, infinitival constructions are restricted to open interrogatives. In subordination, both types of interrogatives allow an infinitival verb: I wondered what to do about it / whether to go by sea or by air (What to do about it? but *Whether to go by sea or by air(?)). The infinitival takes on a modal meaning (I wonder what I should do about it / whether I should go by sea or by air) (see Bresnan, 1970). Infinitival interrogatives correspond to one semantic type of question distinguished by Huddleston \& Pullum (2002: 877-78): the direction question, which is opposed to the information question. Direction questions are questions which require as an answer a directive. In independent interrogative clauses, they contain the modal auxiliary shall (Shall I open the window?). The expected answer is of the kind open the window / don't open the window. When embedded, a direction question is clearly distinguished from an information 
question in so far as it contains an infinitival verb instead of a tensed verb: I asked whether to tell him can only be a direction question whereas I asked whether she told him is an information question.

\subsubsection{Emotive modifiers and clefts}

Emotive modifiers and clefting are still possible in subordinate interrogatives, but with certain restrictions and with a modification in the meaning in some cases. We will come back to those two questions in $\$$ 3.3.2.

\subsection{External characteristics of subordinate interrogatives}

\subsubsection{Interrogative-governing terms}

We shall call the embedding term, or interrogative-governing term, the term which allows the presence of a subordinate interrogative clause. Indeed, subordinate interrogatives have to be licensed by the word under which they are embedded (directly or indirectly). From a semantic point of view, this word has to be compatible with the notion of an abstract content represented by the interrogative clause. The governing word is most often a verb (ask, wonder, know), but it can be other types of words as well (an adjective - sure, aware -, a noun - argument, discussion, issue).

The subordinate interrogative being a content clause, it will have any function dedicated to noun phrases, and others such as extraposed subject or object. We shall mention the most relevant functions hereafter.

Most often, the subordinate interrogative is an essential complement of a verb (subject, direct or indirect object, predicative complement):

[6] Subject: Exactly how children switch to syntax is disputed.

[7] Direct object: I don't know whether he will come.

9 As specified by Huddleston \& Pullum (2002: 977), when the subordinate clause is in subject position, it is not necessarily licensed directly by the verb of which it is the subject or by the head adjective or noun in the predicative complement. It can be licensed indirectly by one of their dependents. For instance, in Whether this is the best solution is open to debate, the licensing term is debate, which is a complement of the adjectival head of the predicative complement (open).

Most interestingly, Huddleston \& Pullum (2002: 266) mention the case of predicative complements in specifying copular constructions. A specifying construction is one of the kind: The chief culprit was Kim, where the semantic roles ascribed to the two items joined by be (here the chief culprit and Kim) are variable on the one hand (the $x$ such as $x$ was the chief culprit) and value on the other hand (Kim). This use of be is opposed to the ascriptive use (His daughter is very bright), where his daughter is a theme and very bright is a property. Other denominations have been used, such as "predicative" vs. "specificational" be (Lambrecht, 2001) or "equative be" (Huddleston, 1971), "identification be" (Quirk et al., 1985). Examples with subordinate interrogatives include The main question is whether we have enough evidence to secure a conviction, where the interrogative clause "serve[s] to identify the main question, the value of the variable expressed in the subject (the $x$ such as $x$ is the main question)" (Huddleston \& Pullum, 2002: 977). In this case, the syntactic function of the interrogative is 
predicative complement. We shall come back to that point in $\S 4$.1.1. because this context is particularly compatible with subject-auxiliary inversion.

41 A subordinate interrogative can also be the complement of an adjective, via a preposition or not (I was uncertain (about) what to do), or the complement of a noun (He had not advanced us one inch in the discovery of whom we were to suspect as a thief).

\subsubsection{Question-orientation vs. answer-orientation}

42 Predicates which license subordinate interrogatives have been variously classified (Baker, 1968; Karttunen, 1977; Karlberg, 1954; Luelsdorff \& Norrick, 1979), but the one classification that will keep our attention is Ohlander's (1986) distinction between question-oriented and answer-oriented predicates. This distinction has consequences both on the possibility to revert subject and auxiliary and on the presence or not of emotive predicates in subordinate interrogatives.

Interrogative-governing predicates are classified according to whether they express knowledge (know) or lack of knowledge (ask, wonder). The first are "concerned with possessing and giving information" (Ohlander, 1986) and can be said to be answeroriented. The second are question-oriented. Of course, this distinction does not just arise from the predicate itself, but also from the elements surrounding it (in particular the presence or not of a negation): I know expresses knowledge, whereas I don't know expresses lack of knowledge and is question-oriented. Ohlander further distinguishes two sub-categories of question-oriented predicates: those which express simple lack of knowledge (I don't know) and those expressing an active desire for knowledge (I'd like to know). The first are called passive question-oriented predicates while the second are active question-oriented predicates.

The consequence of these distinctions is twofold. First, according to Ohlander, only the active question-oriented predicates will accept inversion. Thus, one can say I wonder what did they buy or They wanted to know why did she leave (active question-orientation), but not *They told me why did she leave (answer-orientation) nor *They didn't know why did she leave (passive question-orientation).

Second, the distinction has consequences on the presence or not of emotive predicates in the subordinate interrogative. Expressions such as the hell / the devil / on earth are proscribed in answer-oriented predicates ( ${ }^{*}$ know why the devil they did it). Indeed, these expressions serve to reinforce the speaker's questioning. The same is true of ever (Tell me what ever happened but not *I know what ever happened). The cleft construction may also have an emphatic role, and will therefore also be incompatible with answerorientation and passive question-orientation in this function (? told him what it was I had heard that night. ?I didn't know what it was I had heard that night.). We do find cases of interrogative clauses embedded under do you know which contain a cleft construction, but in this case the role of the cleft is to create suspense, not to emphasize questioning, since the speaker knows the answer to the question, for instance in Do you know who it was we let into the house that day? (...) It was the Devil, Holmes! We have not had a peaceful hour since. (Leonarduzzi, 2004).

Considering that the distinction between question-orientation and answer-orientation is due to the environment of the interrogative-governing term as much as to the term itself, it might be possible to say that the compatibility of subordinate interrogatives 
with emotive predicates is due to the semantics of the whole of the embedding clause rather than the interrogative-governing expression itself.

\subsection{Semantic subordination}

47 As seen in 3.1, syntactic subordination is reflected in semantic subordination. It can be said that in I went out to see if it was the postman the interrogative clause is subordinate not only because it displays the syntactic marks of subordination (if + lack of inversion), but also because the main point of the speaker is not the content of the interrogative clause. This is the case mainly with interrogative-governing terms which are not reporting verbs, for instance see, show, vote, check (they are found in the great majority of cases without inversion):

[8] and did you see what happened to those steps

[9] for example <,> uh does forty-nine show us what was happening there

[10] can we have a vote whether Andy should be Easter bunny

[11] did you check whether there are any inverted cards or is that just too late

\section{The subordinate interrogative: an "unsubordinated" construction in oral speech?}

As mentioned in 3.2.1, interrogative clauses normally lose subject-auxiliary or subjectbe inversion when embedded. And yet, in oral speech especially, it is not infrequent to find inverted interrogative clauses in the presence of an interrogative-governing term and in subordinate position, for instance And then I'll say a few words about where do we go next or I wonder will he help me. We will turn now to the main question of this article: may the interrogative clause in such contexts be said to be subordinate? The main characteristic of a subordinate interrogative is indeed the absence of subject-auxiliary inversion (and of question mark in writing), as in I wondered what you were going to say, so that we might doubt whether the clause is really subordinated when the inversion is used. Leonarduzzi (2004) distinguished several cases of interrogative clauses with inversion in written examples. Here, we focus mainly on oral speech, and add the prosodic aspect.

\subsection{Syntax}

\subsubsection{Syntactic positions}

In which syntactic positions can interrogative clauses with inversions appear? Almost all syntactic positions are allowed, except for subject, where the inversion sounds ungrammatical, even in contexts of question-orientation:

[12] where we are in what numbers of what sexes... is the foundation of a vast statistical picture... ??Where are we is the foundation of a vast picture... (answerorientation)

[13] ?where are we is the question under discussion. ?What are we to do next is to be discussed. (question-orientation)

In the same way, extraposed subject does not seem possible:

[14] ?it is to be discussed what are we to do next. 
51 Most often, the interrogative clause is found in object position (generally direct object) (114 tokens out of 171 in the oral part of our corpus):

[15] therefore one has to uh think uh what are the problems

52 The predicative complement position is also frequent (23 oral tokens), sometimes as the second part of a pseudo-cleft ([17]):

[16] the question of course is how soon can you get there

[17] what I 'm not able to imagine myself is $<,>^{5}$ did you did you ever imagine how

life would be if <,> you did have a father who lived at home

Other positions are possible such as complement of a noun (via a preposition) (9 oral tokens) or apposition (4 tokens):

[18] and then I'll say a few words about where do we go next

[19] I didn't speak about faith as the answer to those inevitable recurring questions

why am I here what is the meaning of my existence

The interrogative clause is often linked to the head noun of a noun phrase through a preposition, especially like:

[20] is there anything else like will you need to use uhm superscripts you know C O

two

[21] and Dick basically said he didn't like it because it was there were questions like

were you given enough guidance and were your personal tutors good enough

Finally, the interrogative can be in the position of a (prepositional) complement of an adjective, but this is very rare in our oral corpus (only 1 token):

[22] you're not constricted in any way to the lengths of fields (...) or how many of a certain type of field do you want

\subsubsection{External marks of subordination}

What cues can be found with inverted interrogatives indicating that the clause is subordinate?

External marks of subordination concern first and foremost the presence of an interrogative-governing expression in the main part of the sentence. We shall speak here only of the cases in which the interrogative clause is in a canonical position behind the interrogative-governing term (examples where they are not in their canonical position will be seen in \$ 5.4.). We will also set apart the case of discourse markers (see § 5.3.). When the interrogative clause is in the position of the object of the verb, of a predicative complement or the complement of a preposition, it is clear that it cannot be deleted without making the sentence ungrammatical. The main clause becomes syntactically and semantically incomplete:

[23] people keep saying where's Louisa (*people keep saying)

[24] the key issue is how do we ensure that local government survives the poll tax (*The key issue is)

[25] I 'm going to obviously have to address this question about what what do we mean by uh learning organisations uhm le learning companies ( ${ }^{*} \mathrm{I}$ 'm going to obviously have to address this question about)

of course, in the last case if we remove the preposition, the sentence remains grammatical (partly due to the presence of this as the determiner of question), even though the reference of this question may not be so clear. 

itself a constituent of a (larger) clause, it will then assume the same function as the other element and (consequently) be subordinate. Let us take this invented example: I asked him if he would come back next week and did he want to go to the swimming-pool. The first interrogative clause is clearly subordinate ( $c f$. if) and is the object of ask. The second interrogative clause is also according to us the object of ask and subordinate. Indeed, it would not be possible in that context to shift back to present tense and change the deictics (see § 4.1.3.): ??I asked him if he would come back next week and do you want to go to the swimming-pool (without the coordination, the main clause form for the interrogative clause is possible, with the value of a quotation: I asked him do you want to go to the swimming-pool). The same holds for noun phrases: I asked him his name and address and did he want a full subscription $=>$ ??I asked him his name and address and do you want a full subscription. This assumption would require further investigation, but if it is correct, then it applies to the following examples, where the interrogative clause is coordinated with a noun phrase which is the object of see in the first case and the complement of the adjective constricted via the preposition to in the second case:

[27] he finds it difficult to look at himself < > > if you see what I mean and see his own responsibility for the marriages not working out or is it anything to do with him [28] you 're not constricted in any way to the lengths of fields or the lengths of records or anything like that or how many of a certain type of field do you want

Dealing with oral speech, though, the rules might not be so strict. If and marks a hesitation, then the speaker might want to change the syntax in the middle of his discourse (see 4.3.1, example [63]).

\subsubsection{Internal marks of subordination}

64 If we consider the internal marks of subordination, we will see that they are very few in our corpus of inverted interrogatives in oral speech. Apart from non-inversion (which goes along with the insertion of if/whether in closed interrogatives), subordination is normally indicated by the backshift in tenses:

[29] "Are you coming to the party?" he asked. => He asked whether I was coming to the party. 
there is inversion, we can also find this mark of subordination. This may be seen when the main verb is in the preterite tense, and the direct question should be in the present. That's what we find in:

[30] when I said were there any nominations I meant for treasurer which corresponds to:

[31] When I said "Are there any nominations?" I meant for treasurer.

Backshift goes hand in hand with a change in shifters when there happens to be shifters:

[32] a recent uh poll asked young uh teenagers who were the great figures of influence in their lives (A recent poll asked: "Who are the great figures of influence in your lives?")

[33] I said did he mind if I came in dry and he said no (= I said: "Do you mind if I come in dry?")

More often than not, though, in our examples either there is no tense agreement between the two clauses or else it cannot be determined whether there is:

[34] Terry pulled her aside and said why are you with these two

[35] and <,, > and so I wonder uh has she picked <unclear-words>

\subsubsection{Subordination and juxtaposition}

71 It follows from what we mentioned about the internal and external marks of subordination that there is a conflict between the two. In cases of inversion, the interrogative clause is rarely internally marked as subordinate, even though it is found in a position of subordination with an interrogative-governing term which would not be complete syntactically (nor semantically) without the interrogative clause.

There are then two ways of considering the question. Either we consider that the two clauses are juxtaposed, since there is no explicit marker of subordination. Arrivé et al. (1986) thus define juxtaposition:

"La juxtaposition est un procédé de mise en relation des phrases ou de constituants, qui consiste à ne pas énoncer explicitement la nature de la relation (contrairement à ce qui se produit dans la coordination et la subordination)." 6 (p. 360)

73 One example they give is Il travaille, il réussit (He works, he is successful) or Il pleut, Paul ne viendra pas (It's raining, Paul will not come). They also consider the two clauses to be juxtaposed in examples such as Je me demande qui vient dîner (I wonder who will come for dinner), where "qui" according to the authors indicates interrogation, but not subordination. Arrivé et al. remain cautious though, mentioning the clause is formally juxtaposed ("[ce sont] formellement des juxtapositions").

74 Another way of solving the problem is to say that subordination is not necessarily marked internally, but depends on external factors. Such is Huddleston's (1994) point of view. He writes:

"There is not always any internal difference between a subordinate clause and a main one. It follows that subordinate clause is essentially a relational category, defined primarily by reference to a larger construction in which it appears rather 
than in terms of its own structure. A subordinate clause is thus one contained

within a larger, superordinate clause." (p. 3853)

$$
\text { made between cited and reported questions. In the following written example, the }
$$
question is cited:

[36] But at a more focused level of analysis one can ask: how do specific new patterns of service or more grandly, service policies, emerge?

It is separated from the verb ask by a colon and is found entirely in the main clause form, with a subject-auxiliary inversion and question mark at the end. The interrogative undergoes no transformation. On the contrary, in:

[37] as I was passing through Newcastle station recently I asked some young women what their views were on the monarchy

$$
\text { the function of specifying predicative complements, which can be produced in the form }
$$
of either a dependent or a main clause:

[38] The main question is whether we have sufficient evidence to secure conviction.

[39] The main question is: Do we have sufficient evidence to secure conviction?

They explain that "the complement is realized by a main clause", and the main clause form is possible because "the question is identified by citing it - and it is cited in the form it has when it stands alone as a sentence". Here is an example from our corpus:

[40] The question for the Conservatives - and for Downing Street, especially - is: what's to be done?

This applies to interrogatives which are in apposition as well, as can be seen in this written example:

[41] Your original question, why he did not report it to the police earlier, has not yet been answered. 

pronounced in a separate tone unit, whereas it should be pronounced inside the same tone unit as the clause containing the embedding term if reported. Let us take this written example first:

[45] He said was I coming and I said yes; he said did I know you, and I said yes.

91 The questions are not cited here, but reported, (see the backshift and the change in shifters: the original questions are Are you coming? and Do you know her?). It seems unlikely that the question could be pronounced in a separate tone unit (??He said / WAS I coming). That's what we find in this clear (uninverted) example of subordination in oral speech, where there is only one tone unit:

[46] I want to ASK what you think about the role of the father today 
[49] Uhm cos I THINK the problem with Dad / his his attitude is / oh WHY don't you

$<,>$ you know just go and get a part-time job /

this card

The questions are cited here, as can be seen from the lack of tense agreement in both example and change in shifters in [49]. It is unlikely that these example would be pronounced with just one tone unit, especially with the interjection oh which further separates the interrogative clause from the clause containing the embedding term (?? his ATtitude is oh why don't go and get a part-time job).

The tone unit boundary is more rarely before be (be is then a prehead):

[50] the key issue / I think / is HOW do we ensure that local government survives / the NEXT two years

In a certain number of the examples, the question is not just cited, as in [48] to [50] above, but actually asked (in the direct form) to the co-speaker, so that there is no possibility whatsoever of including it in the same tone unit as the embedding clause:

[51] my question to you is / HOW on earth is it going to help me in what I very shortly / HAVE got to decide

[52] now you 've you 've anTIcipated my next question again / because my next question was / HOW do you think you viewed women at that time / and HOW does that compare with your views today

[53] the But I THINK what we have to ask ourselves is / ARE we serious / aBOUT our determination / to enSURE that Saddam Hussein leaves Kuwait / a FRIENDly country / which he inVAded with no excuse /

The emotive modifier on earth in [51] is an indication that the speaker is asking the cospeaker the question in the same time as he utters it.

The same is true of appositions in our oral examples: the question is cited and the interrogative clause is pronounced with its own tone unit(s) (do we not all have one father and did not one God create us in the following example):

[54] and MAny wonder / WHEther this first half a verse / DO we not all have one father / DID not one God create us / IS what the people say /

In all the cases seen so far, prosody confirms that the cited (or asked) question is found in the main clause form, being totally separated from the clause containing the interrogative-governing expression and having its own prosody.

When the interrogative clause is a direct object, the question may be cited or not. One of the most frequent verbs used with interrogative clauses containing an inversion is the verb say (68 tokens amounting to almost $40 \%$ ). It is often used in contexts of narration, and the interrogative clause is then cited and pronounced in a separate tone unit. The verb go is also used in that context:

[55] so many people said / ARE you still searching for a business to acquire

[56] you were GOing to say / so / WHERE does he come from

[57] I 've left it / and I 've LOOKED at it every day for the past week going / WHAT is

The interrogative clause is sometimes separated from the main clause by a discourse marker such as well or right:

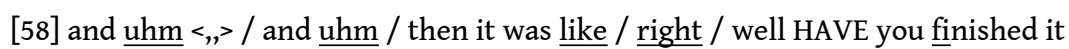

Other verbs follow suit, with the interrogative clause prosodically separated:

[59] so / if you think F / HOW do we know that "on the mat" is a constituent / <,>

we'll LOOK at each of them <,>

[60] you had asked him / DID you receive your payment / from Walling 

agreement between said and were (the original question asked a few minutes before was “(Are there) any other nominations?") (we shall see in $\S 5.1$. why the inversion is necessary after say). The head of the first tone unit is on the interrogative-governing term SAID. We think that the prosodic hierarchy (with the head on said) is a reflection of the syntactic hierarchy, the interrogative clause being subordinate to the verb say, but also of a semantic hierarchy: the main message is: "when I said X, I meant Y". In examples [65] to [67], we also take the absence of a separate tone unit for the interrogative clause to be an indication of its subordinate status. In [65], the speaker mentions the questions he intends to answer (where do we go next? What's going to happen in the future?), but he does not cite them or asks them directly. The introductory term (a few words about) indeed is not a term referring to the notion of question and therefore cannot be used to cite a question (contrary to question or issue for instance). Again, the head of the (first) tone unit is in the main clause on the verb say. [66] and [67] contain the verb be in the interrogative clause. It is equative / identificational here, serving to establish an equivalence between what is on its left and what is on its right, so that the two constituents may be reversed (for instance in My best friend is Peter $\Rightarrow>$ Peter is my best friend) (Pagnoux, 1976; Huddleston, 1971; Quirk et al., 1985). This type of be is particularly likely to trigger inversion in subordinate interrogatives, at least in writing (Leonarduzzi, 2004). This means that inversion with be is not incompatible with subordination. We may think again that the interrogative clause is here syntactically dependent in spite of the inversion. The sentences are pronounced in one tone unit with the head inside the first part of the tone unit (before the interrogative clause). 
110 When there is only one tone unit, there may yet be a reversal of prominence. A clause such as I said may serve as a mere introducer to the interrogative clause (see 5.2.), which will take on more importance than the rest of the sentence. This is especially true in narrative contexts. In this case, I said becomes a prehead, the head being on the interrogative word or auxiliary:

[68] I I said DID he mind if I came in $\underline{\text { dry } / \text { and he SAID no }}$

111 The interrogative clause is here given prominence even though it displays marks of subordination (backshift and change in shifters). If we consider that subordination is a semantic as much as a syntactic notion, then we may say here that from a semantic point of view there is a reversal of subordination. We might describe the relation between the "main" and the "subordinate" clause by saying that the interrogative clause becomes "unsubordinated", that is, it gains greater independence as compared to the preceding cases containing only one tone unit. From a syntactic point of view, these examples are just like the examples [64] to [67] above, since they still contain marks of subordination. With the present tense, the question would clearly be cited, and totally independent (I said DO you mind if I come in $\underline{\text { dry) }}$ (see § 5.1., example [86]).

112 The general tendency then is that when the question is cited or directly asked (and the interrogative clause independent), it is found in a separate tone unit, whereas when it is reported (and the interrogative clause subordinated), it is found in the same tone unit as the embedding term. The head is then found on one element of the embedding clause. An intermediate case is when there is only one tone unit with a head on the whword or interrogative auxiliary, in which case prominence is moved to the interrogative clause. But the separation into tone units may be dependent on other factors, as we shall see in the next section.

\subsubsection{Other functions of prosody}

113 Prosody can have other functions than that of marking subordination. The presence of a tone unit boundary can indeed, depending on the case, be explained by other phenomena such as the length of the sentence or the fact that the speaker wants to emphasize the question itself:

[69] a REcent uh poll / ASKED young uh teenagers / WHO were the great figures of influence in their lives

[70] IF you were to ask me / WHICH party / would MOses or Abraham / have VOted for in a general election / I 'd HAVE to say I really don't know.

In spite of the internal or external marks of subordination in [69] (tense agreement and shifters), the interrogative clause is here prosodically separated. The journalist emphasises the question, but it is clearly reported, and not cited. In [70], the speaker speaks slowly making clear melodic movements on the important words. That is why he pronounces several tone units. Even the interrogative clause is cut into several tone units. It is clear from the following examples, which contain subordinate clauses starting with whether or lacking inversion, that there can be subordination and yet a tone unit boundary before the interrogative clause:

[71] I think perhaps ONE of the questions in the next forty-eight hours / is WHEther or not John Major's uh steamroller / can GO on fast enough...

[72] the ONly question is uhm / whether / as I say we we you NEED an intermediate copy to explain / HOW the uhm how the transmission was made

[73] MY young friend at the end of the table / will ask / on WHAT basis I make these judgements 
115 The tone unit boundary in the first example is due to the length of the sentence (we can clearly hear the speaker taking his breath). In the second example, the first tone unit boundary may be due to hesitation. In the second part of the sentence, the clear fall on explain gives prominence to this word which is important for the speaker (in a context of demonstration) and accounts for the tone unit boundary before how the transmission was made. Let us compare as well those two subordinate interrogatives (containing an infinitive, which here marks subordination since it has nothing to do with interior monologue: see $\S 2.3 .1$ ):

[74] God / you REAlly know how to put someone down don't you

[75] OTherwise there could be another incident / eXACtly like the Antares / with

MORE deaths / because we DON'T know / how to STOP this kind of thing happening

In [74] we can say that prosody is a reflection of the subordinate status of the interrogative clause, the core of the sentence being pronounced in just one tone unit, and the head being inside the main clause on the adverb really. On the contrary, in [75], the lack of knowledge must be emphasized, and the speaker produces two tone units in spite of the subordination.

117 This section showed that prosody confirms that in order to be marked as independent, an interrogative clause will have to be separated from the clause containing the interrogative-governing expression by a tone unit boundary. The question is then cited and really functions like a main clause (except for its relation with an interrogativegoverning expression), having its own prosody. On the contrary, the interrogative clause will normally be inside the same tone unit as the embedding term when it is reported, so that it can be said to be dependent both syntactically and prosodically. Yet, the separation into several tone units cannot always be explained in terms of subordination, since we can find cases in which the interrogative clause is prosodically separated and yet clearly embedded. In other words, prosody may be linked to the status of the interrogative clause (dependent or independent), but it also has its own constraints and functions in its own way.

118 To conclude on the question of the subordination of interrogative clauses displaying subject-auxiliary or subject-be inversion, we think that the interrogative clause may be considered to be subordinate in oral speech, even if it contains an inversion, when there is no tone unit boundary before it and the head is found inside the main clause. The examples of that kind, yet, are much less frequent than cases of clear separation between the interrogative clause and the clause containing the interrogative-governing term.

We will try and explain now what the contexts are that allow inversion.

\section{Contexts licensing inversion}

If we follow Ohlander (1986), the possibility of using an inversion or not in a (subordinate) interrogative clause is subject to semantic constraints. We have seen (§ 3.3.2.) that this linguist distinguishes two categories of interrogative-governing predicates (question-oriented and answer-oriented), and that only the first category is supposed to be compatible with inversion (*I know what did they buy - answerorientation), and among the question-oriented predicates, only the ones of the active type (They wanted to know why did she leave - active question-orientation - but *They 
didn't know why did she leave - passive question-orientation). So inversion is supposed to be compatible with (active) question-orientation. Now, the following example seems to contradict this statement:

[76] do you know where I can get slides from < <> for my <,> presentation

The speaker shows an active desire for knowledge, and yet the inversion does not seem possible: ??Do you know where can I get slides for my presentation. This means that we have to take into account other factors to explain the grammaticality of inversion. It is by turning to pragmatics that we will find cues to possible answers. More precisely, we will look into the discourse function of the clause containing the interrogativegoverning expression.

\subsection{The interrogative-governing term as a reporting verb}

The first obvious context in which we can find an inversion in oral speech is when the interrogative-governing verb is used for reported speech (in the general sense of the term - not in the restricted meaning we gave it in $\$ 4.2$.), especially in narration. If the verb is semantically related to the notion of question itself (ask, wonder), the interrogative clause may be inverted or not. If it contains an inversion, it will be pronounced in a separate tone unit. We come back to the notion of cited question here:

[77] and LOTS of people ask me / well WHY do you go on

[78] TOP of that page / you had asked him / DID you receive your payment / from Walling

Here is an example where the interrogative clause contains no inversion, and is therefore subordinate:

[79] I ASKED William Davis / WHAT effects he thinks / the ROYal Family have on trade

If the reporting verb does not specifically indicate a question (say, go, mean, think), the inversion is compulsory for various reasons. With the verb say, the inversion serves to indicate the illocutionary force of the original speech. Let us take up this example:

[80] when I SAID were there any other nominations / I MEANT for Treasurer

If the speaker had said when I said whether there were any other nominations, it would have meant that the original speech was an assertion, not a question. This is what happens in the following examples where we find the subject + verb order (the verb say is here equivalent to answer the question and not ask the question). We will also note here that (part of) the interrogative clause belongs to the same tone unit as the embedding verb say.

[81] so as NOT to aid the Iraqis / they will NOT say where they've fallen / or HOW many

[82] and uh <,> can you SAY whether that uh injury / would 've occurred / whilst

SOMEbody was being thrown forward

[83] but HAVE we said what that existing plant is doing

Therefore, if the speaker chooses the neutral verb say to report the speech, he needs to use the distinction between inversion and non inversion (clear subordination) to indicate what kind of speech act was performed originally. Now, if we take other verbs, for instance go:

[84] I 've left it / and I 've LOOKED at it every day for the past week going / WHAT is

this $\underline{\text { card }}$ 
the non-inverted form simply becomes ungrammatical ("going what this card is). Again, inversion is compulsory.

In these cases, the prosody will be either two tone units or, as we have seen in $\S$ 4.3., only one tone unit with the reporting verb as a prehead, depending on the semantic weight and complexity of the embedding clause. Here are examples with just one tone unit:

[85] I meant WOULD you like a drink

[86] and he said CAN I pop over

Hanote (2015), studying reporting verbs, finds similar results and concludes that "the acoustic pattern goes with a gradual loss of propositional meaning of the verb say", which is then "used as a mere index between the reported speech clause and an origin."

We may also include here the preposition like used after a noun such as question (see $\S$ 4.1.1. and 4.3.1.):

[87] and DICK basically said he didn't like it / beCAUSE it was / there were questions like / WERE you given enough guidance / and WERE your personal tutors good enough

The function of the preposition is to cite the question. Again, inversion will be compulsory (except maybe when the speaker hesitates): ??there were questions like whether you were given enough guidance.

\subsection{The interrogative-governing term as an introducer}

A second context in which we can find an inversion is when the clause containing the interrogative-governing expression serves as an introducer to the question. The interrogative clause is then in the position of a predicative complement (sometimes in a pseudo-cleft: [89]). Here again, we will find two tone units:

[88] CAN you tell me / HOW did you both get involved in the Mike Heafy project <,,

[89] now WHAT I am asking is / WHY were you not interested to know / WHEther

the scheme was going to proceed

[90] the question of course is / HOW soon can you get there

The difference with examples such as and he said can I pop over, in which we might consider the verb say also to be used simply as an introducer to the question, is that first of all these are not contexts of narration, and secondly that the introductory clause does have some semantic weight in itself, which justifies the presence of the second tone unit. The speaker really asks the question to the addressee.

\subsection{The interrogative-governing term as a discourse marker}

Verbs such as know or mean are likely, in the proper context, to be used as discourse markers. The expressions are you know and I mean. The verb then undergoes semantic bleaching / desemanticisation. The expression is mobile and can be placed at the beginning, in the middle or at the end of a sentence. It has no other function than to organise the flow of discourse. When you know / I mean is a discourse marker, the interrogative clause, being independent, will of course be produced with an inversion:

[91] and then you know WILL I have to unscramble everything <,>

[92] mean WHY do people want to become monopolies

[93] I mean DOES it matter 
[94] now if you think about it / I mean COULD you have anything more stupid

[95] I mean you know IS there something incomplete

Prosodically, I mean and you know are deaccented and can be found in the same tone unit as the interrogative clause, as in the examples above.

On the contrary, if you know has its full lexical meaning, it will not be compatible with inversion, being answer-oriented:

[96] you KNOW what I mean (*You know what do I mean)

[97] you KNOW what it's like (*You know what is it like)

In this sense, you know is also very frequent in the interrogative form (do you kow). The interrogative clause (after do you know) is again subordinate and generally uninverted. The speaker really means do you know something. If there is just one tone unit, know is normally the head of the tone unit, the nucleus being somewhere inside the interrogative clause:

[98] do you KNOW what led you to write a novel

Mean works differently and can be found with inversion even with its full semantic meaning, since it may serve to reformulate a question (it is neither question- nor answer-oriented). In our corpus, it then always has a different form than I mean (the subject and/or the tense will be different):

[99] I meant / WOULD you like a drink

[100] well I DON'T think you can negotiate / if by negotiAtions you mean / CAN we

allow Saddam Hussein / to HOLD on to part of Kuwait

[101] you know it can mean / WHAT do the French call la la Manche

It is to be noted that here mean belongs to a separate tone unit. If the expression is $I+$ verb in the present tense, it becomes more ambiguous, being closer to a discourse marker, and always found with inversion. The verb certainly undergoes a reduction of the tense vowel /i:/ if a discourse marker. Further studies on discourse markers would be necessary here.

\subsection{The interrogative-governing term as a tag}

Another clear context which licenses inversion in interrogative clauses in the presence of an interrogative-governing term is when the latter is used as a tag. It is no longer in its canonical position (before the interrogative clause) but is inserted in the middle of the interrogative clause or at the end of it. The expressions here are do you know, do you think, and expressions with wonder or other reporting verbs:

[102] and d' you d' you have a <,> REAsonable diet d' you think

[103] WHICH part is he from do you know

[104] ARE we getting paid for this did she say the addressee (= do you think that / do you know if / did she say whether) or states a psychological state (one wonders: see [105]), so that the verb retains its full meaning. The tag is included inside the same tone unit as the interrogative clause and is dependent on it. It is pronounced as a tail if at the end. The end of the sentence comes as an afterthought. If we try to re-establish the canonical order, it becomes very different. In the first example above, the interrogative would become a that-clause (do you think (that) you have a reasonable diet); in the second, inversion would no longer be 
grammatical (do you know which part he is from - as in Emma do you know when his office hours are - but not *do you know which part is he from: see $\$$ 5.3.) and in the third, inversion would on the contrary become compulsory because of the fact that the verb say is not a question word (did she say whether we were getting paid for this $\neq$ did she say are we getting paid for this: see $\S$ 5.1.). The reasons for these various behaviours of the embedding terms are yet to be determined.

The tag can also be found in the middle of the interrogative clause:

[105] and who / ONE wonders / IS to gainsay them

[106] uh WHICH you ask is the more authentic / the MORE mandated / by tradition

/ reLIgious moderation <,> / or reLIgious extremism <,>

In this case it can either have a tone unit of its own, interrupting the prosody of the interrogative clause ([105]), or be completely integrated into the prosody of the interrogative clause ([106]).

For further comments on the prosody of comment clauses in particular, and parentheticals in general, see for instance Dehé (2009).

146 In all the cases of inversion seen in this section, it is of course the interrogative clause which becomes the main part of the message, so that we might think that there is a reversal of the roles between subordinate and main clause, at least from a semantic point of view.

\section{Conclusion}

In our corpus, most of the examples of interrogative clauses containing an inversion are cited rather than reported and pronounced in two tone units. The interrogative clause may then be said to be independent. When the embedding term is not in its canonical position (before the interrogative clause), it is particularly clear that the interrogative clause is not subordinated. But even if the examples are fewer, interrogative clauses may also sometimes be considered to be subordinated in spite of the inversion, as can be seen from syntactic marks of subordination (backshift and change in shifters) as well as prosody (the interrogative clause being in that case part of the same tone unit as the main clause). But prosody alone is not sufficient to say whether the interrogative clause is subordinate or not, since it has its own functioning and is not necessarily used as a marker of subordination. What is particular about interrogative clauses is that they can be found after an embedding term and so (apparently at least) subordinated, and yet in the main clause form, that is to say with an inversion and possibly no internal marks of subordination. It seems then that the subordinate interrogative may well be said to show signs of "unsubordination". Some French linguists analysed similar examples in French (for instance je t'ai dit à Marseille qu'est-ce qui s'est passé $e^{8}$ ), considering them to be mixed forms and conclude that the traditional categories for analysing written speech are not efficient for oral speech (see Gadet, to appear).

Another point we have investigated, but which requires further study, is the constraints on inversion in oral speech. We have seen that the grammaticality of inversion depends on pragmatic factors as much as semantic ones. Inversion is present in contexts where the interrogative-governing expression plays one of the following 
roles: reporting verb, introducer, discourse marker or tag. It may even become compulsory in some cases.

\section{BIBLIOGRAPHY}

Arrivé, M., Gadet, F., Galmiche, M. (1986). La grammaire d'aujourd'hui. Guide alphabétique de linguistique française. Paris : Flammarion.

Aarts, B., Nelson, G., Wallis, S. (2002). Exploring natural language: the British component of the International Corpus of English. Amsterdam: John Benjamins. http://www.ucl.ac.uk/englishusage/projects/ice-gb/

Baker, C. L. (1968). Indirect questions in English. PhD, Université de l'Illinois: Urbana, Illinois.

Boersma, P., Weenink, D. (2001). PRAAT, a system for doing phonetics by computer, Glot International 5 (9/10), pp. 341-345. http://www.praat.org

Bresnan, J. (1970). “On Complementizers: Toward a Syntactic Theory of Complement Types”, in Foundations of Language, $\mathrm{n}^{\circ}$ 6, pp. 297-321.

Butters, R. (1974). "Variability in Indirect Questions", in American Speech: A Quarterly of Linguistics Usage, $n^{\circ} 49$, pp. 57-62. Athens: GA.

Cruttenden, A. (1986). Intonation. Cambridge: CUP.

Dehé, N. (2009). “Clausal parentheticals, intonational phrasing, and prosodic theory”, Journal of Linguistics 45(3), pp. 569-615. Cambridge: Cambridge University Press.

Delais-Roussarie, E., Herment, S. (2018). «Intonation et interprétation des questions : un puzzle pluridimensionnel », in M-J. Béguelin, A. Coveney, A. Guryev (éds.), L'interrogative en français, pp. 51-78. Berne : Peter Lang, Collection Sciences pour la Communication.

Gadet, F., to appear, "Nouveau corpus d'oral, nouvelles données, nouveaux questionnements" in Cappeau, P. (ed), Une grammaire à l'aune de l'oral ? Rennes: PUR.

Halliday, M.A.K. (1967). Intonation and Grammar in British English. The Hague-Paris: Mouton.

Hanote, S. (2015). “Are reporting verbs special cases of parentheticals?”, in J. Glikman, M. Avanzi, St. Schneider (eds.), Parenthetical Verbs: Hypotaxis, Parataxis or Parenthesis, pp. 257-286. Linguistische Arbeiten, Berlin / New York, De Gruyter.

Hedberg N., Sosa, J. M. (2002). “The Prosody of Questions in Natural Discourse” in B. Bel \& I. Marlien (éds) Proceedings of Speech Prosody 2002. Aix-en-Provence: Laboratoire Parole et Langage.

Herment, S. et al. (2014). "Modelling interlanguage intonation: the case of questions", in Proceedings of the 7th International Conference on Speech Prosody, Dublin, Ireland, pp. 492-496.

Huddleston, R. (1971). The Sentence in Written English. A Syntactic Study based on an analysis of scientific texts. Cambridge: CUP.

Huddleston, R. (1994). "Sentence Types and Clause Subordination”, in R. Asher (éd), The Encyclopaedia of Language and Linguisics, vol. VII, pp. 3851-3856. Oxford: Pregammon Press. 
Huddleston, R., Pullum, G. (2002). The Cambridge Grammar of the English Language, 3d edition. Cambridge: CUP.

Jespersen, O. (1954). A Modern English Grammar on Historical Principles. Londres: George, Allen and Unwin LTD.

Karlberg, G. (1954). "The English Interrogative Pronoun. A Study of their Syntactic History”, in Gothenburg Studies in English III. Stockholm: Almqvist and Wikbsell / Lund.

Karttunen, L. (1977). "Syntax and Semantics of Questions", in Linguistics and Philosophy, n 1, pp. 3-44.

Lambrecht, K. (2001). “A framework for the analysis of cleft constructions”, in Linguistics 3(3), pp. 463-516.

Leonarduzzi, L. (2000). La subordonnée interrogative en anglais contemporain. Thèse de doctorat, Université de Provence, Aix-Marseille I, Aix-en-Provence, France.

Leonarduzzi, L. (2004). La subordonnée interrogative en anglais contemporain. Aix-en-Provence : PUP.

Luelsdorff, P. A., Norrick, N. R. (1979) "On if and whether complementation", in Linguistische Berichte, $\mathrm{n}^{\circ} 62$, pp. 25-47.

Ohlander, S. (1986). "Question-orientation versus answer-orientation in English interrogative clauses," in D. KastoEky \& A. Szwedek (éds), Linguistics across Historical and Geographical Boundaries: in Honour of Jacek Fisiak on the occasion of his $50^{\text {th }}$ birthday, Vol. 2, pp. 963-982. Berlin: Mouton de Gruyter.

Pagnoux, M. (1976). Les structures relatives en anglais contemporain. Thèse, Université de Lille III : atelier de reproduction des thèses.

Pope, E. (1976). Questions and answers in English. La Haye / Paris : Mouton.

Quirk, R. et al. (1985). A Comprehensive Grammar of the English Language, $12^{\text {th }}$ edition. London: Longman.

Turnbull-Sailor C. (2007). Syntactic Patterns of Embedded Wh- Clauses. PhD, University of Kansas. Wells, J. (2006). English Intonation, An Introduction. Cambridge: Cambridge University Press.

\section{NOTES}

1. We would like to thank both reviewers for their useful comments and suggestions.

2. This PhD was defended in 2000 and published in a reduced form in 2004.

3. "[Subordination is] a one-way, asymmetrical relationship between two clauses, one of which receives its function from the other." [our translation].

4. This assumption is based on intuition and seems to be confirmed by the fact that no such examples were found in the corpora. The examples should be tested with native speakers.

5. In ICE-GB, the sign <,> indicates a short pause, and <,> a long pause.

6. "Juxtaposition is the bringing into relation of clauses or constituents without explicitely indicating the nature of the relationship (contrary to what happens with coordination and subordination)." [our translation].

7. "[They are] formally juxtapositions." [our translation]. 
8. "I told you in Marseille what has happened" (= Did I tell you what has happened in Marseille) [our translation]. "qu'est-ce que" is a direct interrogative form in French. In English, what has happened is used both for subordinate and non-subordinate interrogative clauses.

\section{ABSTRACTS}

This paper takes up a chapter of the $\mathrm{PhD}$ La subordonnée interrogative en anglais contemporain (Leonarduzzi 2000) prepared under the supervision of Françoise Dubois-Charlier. It deals with the question of the subordination of interrogative clauses, adding one essential feature prosody. The main object of the paper is to try and determine how far the interrogative clause can be considered to be subordinate when displaying subject-auxiliary or subject-be inversion in the presence of an interrogative-governing term in oral speech. The study is mainly based on tokens drawn from the oral component of ICE-GB.

Cet article revient sur un chapitre de la thèse La subordonnée interrogative en anglais contemporain (Leonarduzzi 2000) effectuée sous la direction de Françoise Dubois-Charlier. Il aborde la question de la subordination des propositions interrogatives en ajoutant une dimension essentielle : celle de la prosodie. Nous nous attachons ici à déterminer les critères qui permettent de déterminer si une interrogative contenant une inversion sujet-auxiliaire ou sujet-be est subordonnée ou non lorsqu'elle se trouve en présence d'un terme introducteur de subordonnées interrogatives en discours oral. L'étude est essentiellement basée sur la composante orale du corpus d'anglais britannique ICE-GB.

\section{INDEX}

Keywords: subordination, subordinate interrogative clause, syntax, prosody, pragmatics, inversion

\section{AUTHORS}

\section{LAETITIA LEONARDUZZI}

Aix Marseille Université, CNRS, LPL, Aix-en-Provence, France

\section{SOPHIE HERMENT}

Aix Marseille Université, CNRS, LPL, Aix-en-Provence, France 